\title{
Biochemical investigation of kraft lignin degradation by Pandoraea sp. B-6 isolated from bamboo slips
}

\author{
Yan Shi $\cdot$ Liyuan Chai $\cdot$ Chongjian Tang $\cdot$ \\ Zhihui Yang $\cdot$ Yu Zheng $\cdot$ Yuehui Chen $\cdot$ \\ Qingxiu Jing
}

Received: 19 March 2013/Accepted: 9 May 2013/Published online: 23 July 2013

(C) The Author(s) 2013. This article is published with open access at Springerlink.com

\begin{abstract}
Kraft lignin (KL) is the major pollutant in black liquor. The bacterial strain Pandoraea sp. B-6 was able to degrade KL without any co-substrate under high alkaline conditions. At least $38.2 \%$ of chemical oxygen demand and $41.6 \%$ of color were removed in 7 days at concentrations from 1 to $6 \mathrm{~g} \mathrm{~L}^{-1}$. The optimum $\mathrm{pH}$ for $\mathrm{KL}$ degradation was 10 and the optimum temperature was $30^{\circ} \mathrm{C}$. The greatest activities of $2,249.2 \mathrm{U} \mathrm{L}^{-1}$ for manganese peroxidase and $1,120.6 \mathrm{U} \mathrm{L}^{-1}$ for laccase were detected on the third and fifth day at $\mathrm{pH} 10$, respectively. Many small molecules, such as cinnamic acid, ferulic acid, 2-hydroxy benzyl alcohol, and vanillyl methyl ketone, were formed during the period of KL degradation based on GC-MS analysis. These results indicate that this strain has great potential for biotreatment of black liquor.
\end{abstract}

Keywords Pandoraea sp. B-6 - Kraft lignin · Degradation · Black liquor

\footnotetext{
Y. Shi $\cdot$ L. Chai $(\varangle) \cdot$ C. Tang $\cdot$ Z. Yang ·

Y. Zheng · Y. Chen · Q. Jing

School of Metallurgical Science and Engineering,

Central South University, Changsha 410017, Hunan,

People's Republic of China

e-mail: Liyuan.chai@yahoo.com.cn; Lychai@csu.edu.cn

Y. Shi

e-mail: shiyzy@126.com

L. Chai $\cdot$ C. Tang $\cdot$ Z. Yang

Chinese National Engineering Research Center for

Control and Treatment of Heavy Metal Pollution,

Changsha 410017, People's Republic of China
}

\section{Introduction}

Lignin is the most abundant aromatic compound on earth and is second only to cellulose in its contribution to living terrestrial biomass [1]. The structural complexity of lignin, its high molecular weight, and its insolubility make its degradation difficult [2]. The biological degradation of lignin is critical to the biospheric carbon and oxygen cycle [3] and is responsible for much of the natural destruction of wood in use. Applications utilizing lignin-degrading organisms or isolated enzymes provide environmentally friendly technologies for the pulp and paper industry and for the treatment of many xenobiotic compounds and dyes [4].

Despite the resistance of lignin to degradation, a number of fungi are able to breakdown lignin. The best characterized degraders are white-rot fungi, in particular Phanerochaete chrysosporium and Phlebia radiata [5], although brown-rot and soft-rot fungi are also able to degrade lignin. White-rot fungi secrete phenol oxidases, including lignin peroxidase, manganese peroxidase, and laccase, that attack lignin. These enzymes act through radical reactions [6]. Basidiomycetous fungi are the most efficient lignin degraders currently known, but there is as yet no commercial biocatalytic process for lignin depolymerization [7]. Bacteria also have versatile pathways for degradation of aromatic substances, from simple phenols to highly complex lignin and related xenobiotic substances.

Bacterial degradation is also attractive in part because fungal lignin degradation results in the formation of low molecular weight, mostly aromatic carboxylic acids, that may be further metabolized by bacteria [8]. There are literature reports of lignin degradation by a number of bacterial species [9-12]. Recent work also indicates that Sphingomonas paucimobilis SYK-6, known to degrade lignin-derived aromatic compounds, degrades lignin [6]. 
More than 10 lignin-degrading bacteria from several genera of Serratia, Citrobacter, Klebsiella, Paenibacillus, Aneurinibacillus, and Bacillus were isolated from the sludge of pulp paper mill and investigated for the ability to degrade lignin [13, 14] and lignin degradation products $[15,16]$. Some of those bacteria have been used in the treatment of black liquor [17-19]. The structure of natural lignin is very complex and intact lignin is not commercially available. Because of similarities to natural lignin, kraft lignin (KL) has been widely used for lignin-related studies. KL is also the major by-product in the relatively high alkaline effluent (black liquor) generated by the pulp and paper industry [20]. Although several bacterial strains had been reported to degrade KL, only a few strains are able to degrade KL from pulp and paper industry waste [17, 18].

The Gram-negative bacterial strain Pandoraea sp. B-6 was isolated from eroded bamboo slip steeping fluid derived from Kingdom $\mathrm{Wu}$ during the Three-Kingdoms Dynasty of ancient China (A.D. 220-280). Pandoraea sp. B-6 can use KL and lignin derivatives as its sole carbon sources under high alkaline conditions. In this study, the abilities of Pandoraea sp. B-6 and extracellular ligninolytic enzymes to degrade KL were investigated. The low molecular weight compounds resulted from KL degradation were identified by GC-MS analysis. The partial $16 \mathrm{~S}$ rRNA gene sequence of the microorganism has been deposited in GenBank with the accession number of JN128829.1. This work indicates that Pandoraea sp. B-6 has significant potential for use in lignin degradation and black liquor biotreatment.

\section{Materials and methods}

Bacterial strain and culture conditions

The bacterial strain Pandoraea sp. B-6 was isolated from the steeping fluid of eroding bamboo slips [21]. The bacteria were grown in the Luria-Bertani broth medium at $30{ }^{\circ} \mathrm{C}$ with shaking at $120 \mathrm{rpm}$ until the optical density at $600 \mathrm{~nm}\left(\mathrm{OD}_{600}\right)$ of inoculum reached approximately 1.0. Two-millimeter aliquots of this culture were aseptically inoculated into triplicate flasks containing $100 \mathrm{ml}$ sterile $\mathrm{KL}$ mineral salt medium $\left(3 \mathrm{~g} \mathrm{KL}, 2 \mathrm{~g}\right.$, $\left(\mathrm{NH}_{4}\right)_{2} \mathrm{SO}_{4}, 1 \mathrm{~g}$ $\mathrm{K}_{2} \mathrm{HPO}_{4}, 1 \mathrm{~g} \mathrm{KH} \mathrm{PO}_{4}, 0.2 \mathrm{~g} \mathrm{MgSO}_{4}, 0.1 \mathrm{~g} \mathrm{CaCl}_{2}, 0.05 \mathrm{~g}$ $\mathrm{FeSO}_{4}, 0.02 \mathrm{~g} \mathrm{MnSO}_{4}$ in 1 litre distilled water, $\mathrm{pH}$ 7.0). The flasks were incubated at $30{ }^{\circ} \mathrm{C}$ with shaking speed of $120 \mathrm{rpm}$ for 7 days. These cultures were used to investigate the effects of the temperature, $\mathrm{pH}$, and initial $\mathrm{KL}$ concentration on KL degradation by Pandoraea sp. B-6. The $\mathrm{pH}$ values were monitored with a $\mathrm{pH}$ meter during adjustment of buffer to required $\mathrm{pH}$.
Bacterial growth and COD measurements

Degradation experiments were carried out on a rotary shaker $(120 \mathrm{rpm})$ under aerobic conditions at $30{ }^{\circ} \mathrm{C}, \mathrm{pH} 10$ for 7 days. The rate of Pandoraea sp. B-6 growth was determined by measuring the $\mathrm{OD}_{600}$ of cultured samples withdrawn at intervals on a Hitachi U-4100 spectrophotometer using centrifuged uninoculated medium as a control in $1.0-\mathrm{cm}$ cuvette path length cells. The control and cultured samples were centrifuged at $10,000 \mathrm{rpm}$ for $10 \mathrm{~min}$ to remove biomass and suspended solids, and the chemical oxygen demand (COD) of the supernatant was measured by the fast digestion-spectrophotometric method (the Environmental Protection Industry Standard of the People's Republic of China, HJ/T 399-2007).

Measurement of the color removal

The intensity of color, before and after incubation, was determined by the standard method of the Canadian Pulp and Paper Association [22]. The amount of color present was determined spectrophotometrically and was related to the absorbance of a PtCo standard solution at the same wavelength. The samples were centrifuged at 10,000 rpm for $10 \mathrm{~min}$ to remove suspended solids. The $\mathrm{pH}$ of the supernatant was then adjusted to 7.6, and thereafter the absorbance at $465 \mathrm{~nm}$ against distilled water was measured using the spectrophotometer. The absorbance values $(A)$ were then transformed into color units (PtCo) as follows:

$\mathrm{CU}(\mathrm{PtCo})=500 \times A_{2} / A_{1}$

where $A_{1}$ corresponds to the $A_{465}$ of a 500-CU platinumcobalt standard solution (0.132); and $A_{2}$ is the absorbance of the effluent sample.

Determination of the ligninolytic enzyme activity

An 1-ml aliquot of culture supernatant, prepared by centrifugation $(10,000 \mathrm{rpm}$ for $10 \mathrm{~min})$, was used to determine the activity of laccase, lignin peroxidase, and manganese peroxidase. Laccase activity was determined using 2,2'-azino-bis-(3-ethylbenzthiazoline6-sulphonic acid) (ABTS) as substrate with monitoring at $420 \mathrm{~nm}\left(\varepsilon_{420}=36,000 \mathrm{~mol}^{-1} \mathrm{~cm}^{-1}\right)$ [23]. Lignin peroxidase activity was determined by the peroxidedependent oxidation of $2 \mathrm{mM}$ veratryl alcohol to veratraldehyde followed at $310 \mathrm{~nm} \quad\left(\varepsilon_{310}=9.300\right.$ $\mathrm{mol}^{-1} \mathrm{~cm}^{-1}$ ) [24]. Manganese peroxidase activity was assayed by monitoring the oxidation of 2,6-dimethoxyphenol (2, 6-DMP) to coerulignone at $469 \mathrm{~nm}$ $\left(\varepsilon_{469}=49,600 \mathrm{~mol}^{-1} \mathrm{~cm}^{-1}\right)$ [25]. The value of $\varepsilon$ was obtained using the Beer-Lambert law: 
$\log \left(I_{0} / I\right)=\varepsilon C l$

where $\log \left(I_{0} / I\right)$ is absorbance, $\varepsilon$ is the proportional coefficient of optical absorption, $C$ is the concentration of the sample, and $l$ is the optical path length of the cuvette.

Analysis of small molecule intermediates from KL degradation through GC-MS

Cultured samples of bacteria containing $1 \mathrm{~g} \mathrm{~L}^{-1} \mathrm{KL}$ in the medium were periodically withdrawn and centrifuged at $12,000 \mathrm{rpm}$ for $10 \mathrm{~min}$. Supernatants were acidified to $\mathrm{pH}$ 2.0 with $6 \mathrm{mmol} \mathrm{L}^{-1} \mathrm{HCl}$ and then extracted with equal volume of ethyl acetate. Three portions of the extraction were collected, dehydrated over anhydrous $\mathrm{Na}_{2} \mathrm{SO}_{4}$, filtered though filter paper, and evaporated at $40{ }^{\circ} \mathrm{C}$ under vacuum on a rotary vacuum evaporator. Then, $0.1 \mathrm{ml}$ dioxane and $0.01 \mathrm{ml}$ pyridine were added to the samples followed by silylation with $0.05 \mathrm{ml}$ trimethylsilyl (TMS). The mixture was heated at $60{ }^{\circ} \mathrm{C}$ for 15 min with periodic shaking to dissolve residues. GC-MS analysis of organic extracts residues was conducted using the method reported previously [26]. The identification of low molecular weight compounds as TMS derivatives derived from bacterial degradation was done by comparing their mass spectra with that of the National Institute of Standards and Technology (NIST) library available through the instrument manufacturer and also by comparing the retention time (RT) with those of authentic compounds when available.

\section{Results and discussion}

Effects of temperature and $\mathrm{pH}$ on $\mathrm{KL}$ degradation by Pandoraea sp. B-6

The degradation of KL ( $\left.3 \mathrm{~g} \mathrm{~L}^{-1}\right)$ by Pandoraea sp. B-6 as a function of temperature is shown in Fig. 1a. The extent of $\mathrm{KL}$ degradation was significantly different at $15{ }^{\circ} \mathrm{C}$ than at $45{ }^{\circ} \mathrm{C}$. The optimum temperature for degradation under these conditions was $30{ }^{\circ} \mathrm{C}$. Approximately, $54.5 \%$ of $\mathrm{KL}$ remained after 7 days in the bacterial culture at $30{ }^{\circ} \mathrm{C}$. Degradation efficiency decreased dramatically at both higher and lower temperatures with only $5.4 \%$ degraded after 7 days at $45{ }^{\circ} \mathrm{C}$.

The effect of $\mathrm{pH}$ on KL degradation is shown in Fig. $1 \mathrm{~b}$. The efficiency of $\mathrm{KL}\left(1 \mathrm{~g} \mathrm{~L}^{-1}\right)$ was higher under alkaline conditions ( $\mathrm{pH} 9-11)$ than at lower $\mathrm{pH}$ values. There was no significant difference in the amount of KL degradation at $\mathrm{pH} 9$ vs. 10 , with 44.7 and $46.7 \% \mathrm{KL}$ remaining after 7 days, respectively. The optimum value was 10 .

Treatment of bleached kraft mill effluent (black liquor) with white-rot fungi has been well characterized
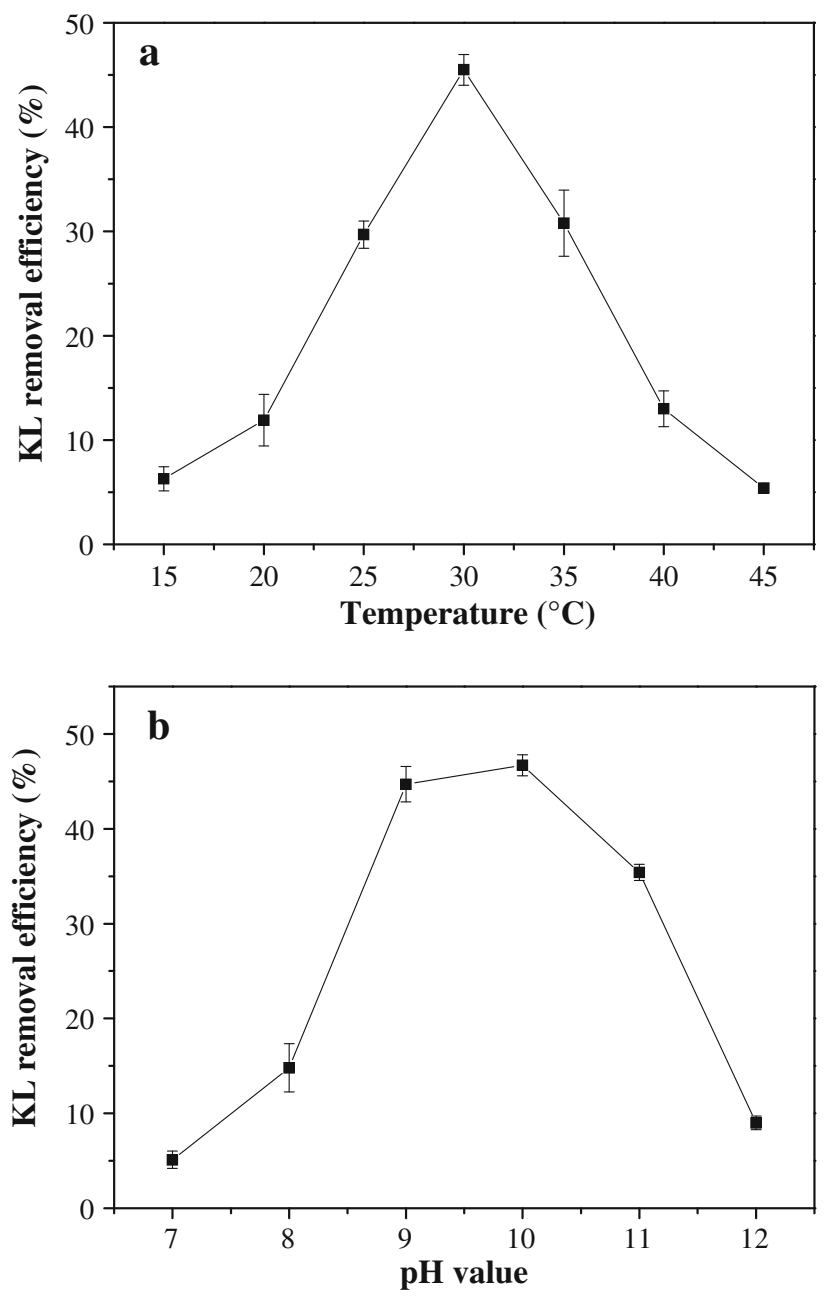

Fig. 1 Effect of temperature (a) and $\mathrm{pH}$ (b) on kraft lignin degradation by Pandoraea sp. B-6. Data are presented as mean of three replicates with SE

[17]. The fungi require low $\mathrm{pH}$ (4-5) for growth and enzyme activity. The solubility of high molecular weight lignin and derivatives are reduced at low $\mathrm{pH}$ compared to alkaline $\mathrm{pH}$, and the $\mathrm{pH}$ values of pulp and paper effluent are generally high (10-13). Thus, it would be most economical to develop a degradation method that is effective at alkaline $\mathrm{pH}$. Previously reported optimum $\mathrm{pH}$ values for KL lignin degradation by bacterial strains varied from 7 to 8.5. For example, the optimum $\mathrm{pH}$ of Aneurinibacillus aneurinilyticus was 7.6 [15], that for Comamonas sp. B-9 was 7 [26], and that for a Bacillus strain was 7.6 [17]. For Streptomyces strains, pH optimum ranged from 7.8 to 8.5 [27]. Our results indicate that Pandoraea sp. B-6, with its optimum KL degradation activity at high $\mathrm{pH}$, has a significant advantage for application in black liquor biotreatment compared with other microorganisms. 
Bacterial growth and KL degradation

In order to determine the optimal KL concentration for the degradation reaction, Pandoraea sp. B-6 growth was evaluated under seven initial $\mathrm{KL}$ concentrations ranging from 1 to $6 \mathrm{~g} \mathrm{~L}^{-1}$. Pandoraea sp. B-6 grew fairly well at concentrations from 1 to $6 \mathrm{~g} \mathrm{~L}^{-1}$ (Fig. 2a). The OD value
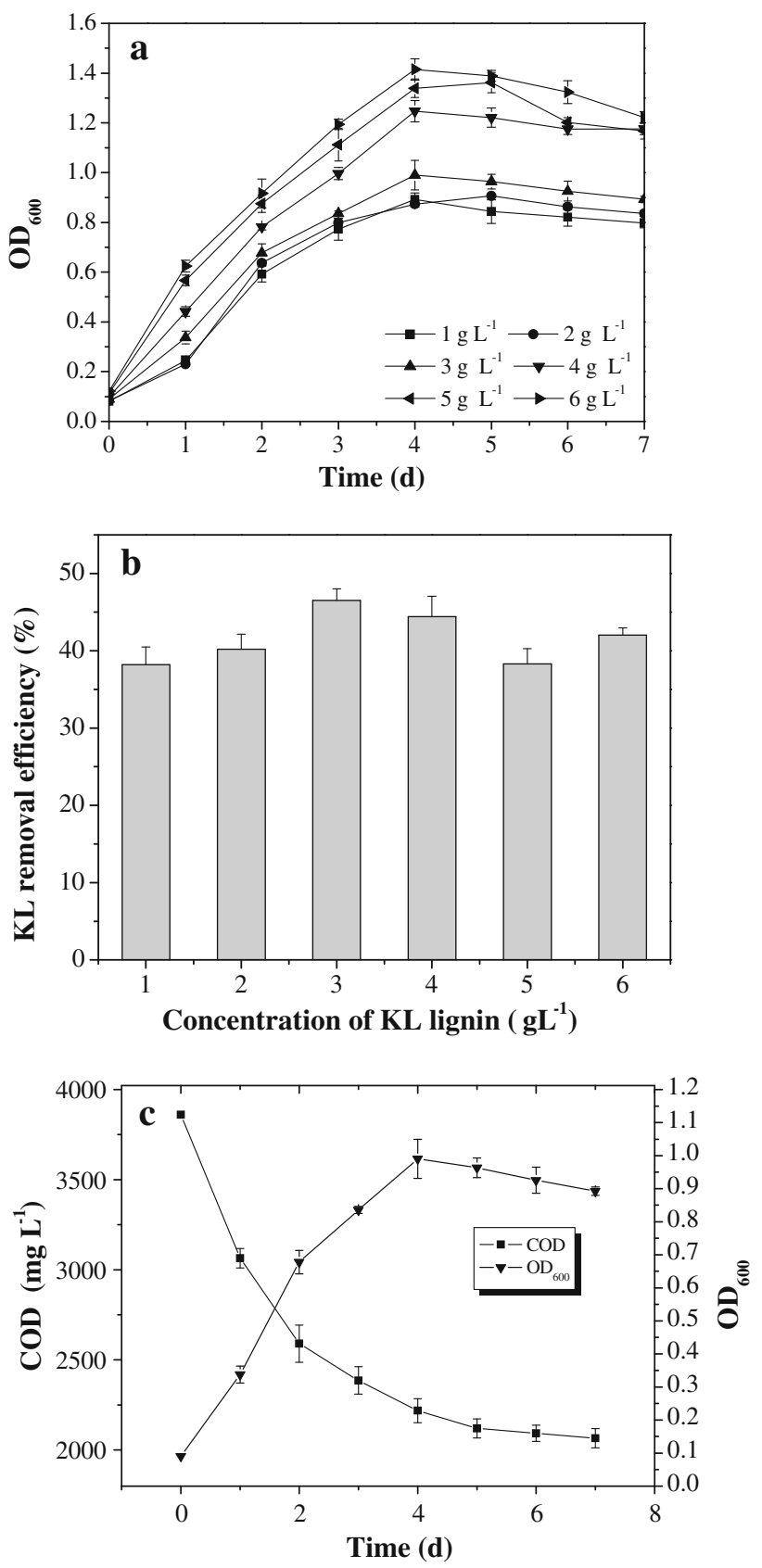

Fig. 2 Pandoraea sp. B-6 growth and kraft lignin degradation. a Pandoraea sp. B-6 growth in different initial concentration, b kraft lignin removal rate by Pandoraea sp. B-6 on day 7 in different initial concentration, and $\mathbf{c}$ Pandoraea sp. B-6 growth and COD reduction in $2 \mathrm{~g} \mathrm{~L}^{-1} \mathrm{kraft}$ lignin. Data are presented as mean of three replicates with SE of the cultured sample increased with increasing initial KL concentration. KL degradation at each initial concentration surpassed $38 \%$ after days in culture (Fig. 2b), but there was no obvious correlation between the initial concentration and extent of $\mathrm{KL}$ degradation. The highest percent degradation was $46.5 \%$ at the initial KL concentration of $3 \mathrm{~g} \mathrm{~L}^{-1}$; the greatest degradation capacity was $2.52 \mathrm{~g} \mathrm{~L}^{-1}$ for the initial $\mathrm{KL}$ concentration of $6 \mathrm{~g} \mathrm{~L}^{-1}$.

The growth of Pandoraea sp. B-6 and its ability to degrade KL in the nutrient medium with the KL concentration of $3 \mathrm{~g} \mathrm{~L}^{-1}$ were investigated in detail. The result is shown in Fig. 2c. Pandoraea sp. B-6 growth was rapid during the first 2 days in culture and reached the maximum on the fourth day. KL degradation occurred mainly during the first 2 days of culture during the exponential growth phase. Accordingly, the maximum KL removal rate of $795.7 \mathrm{mg} \mathrm{L}^{-1}$ day $^{-1}$ was recorded during this period. From the third day, the removal rate decreased gradually, but KL degradation continued. The COD value was $3,860 \mathrm{mg} \mathrm{L}^{-1}$ on the first day of culture and was $2,065.1 \mathrm{mg} \mathrm{L}^{-1}$ on the seventh day. These results with Pandoraea sp. B-6 differ from those of other bacteria such as Citrobacter strains. Other strains initially use glucose and peptone as carbon source and subsequently utilize lignin as a co-metabolite [18]. KL can be used as the sole carbon source by Pandoraea sp. B-6; accordingly, it was metabolized during the initial growth stage to provide carbon and energy sources. Like KL degradation by Pandoraea sp. B-6, Comamonas sp. B-9 [26] and Streptomyces viridosporus [11] metabolize KL during the initial growth phase and also have a high capacity for KL degradation. These bacterial species metabolize KL throughout the whole life cycle for their growth; therefore, the efficiency and total amount of lignin degradation are higher than with strains that use lignin as a co-metabolite. Pandoraea sp. B-6 can be directly used for treatment of black liquor without need for a supplementary carbon source that would increase the COD load of the system.

\section{KL decolorization}

The decolorization of $\mathrm{KL}$ at different initial concentrations at $\mathrm{pH} 10$ after 7 days in culture with Pandoraea sp. B-6 is shown in Fig. 3. Percent decolorization at initial KL concentrations from 1 to $6 \mathrm{~g} \mathrm{~L}^{-1}$ ranged from 41.6 to $47.9 \%$. The difference was $<7 \%$, indicating that the effect of initial KL concentration on the Pandoraea sp. B-6 decolorization is negligible. The percent decolorization of different initial concentrations of $\mathrm{KL}$ at $\mathrm{pH} 10$ over 7 days in culture is shown in Table 1. The decolorization of KL was mainly observed in the first 2 days, consistent with fast bacterium growth and COD reduction. Moreover, like COD reduction, KL decolorization was continued after the 


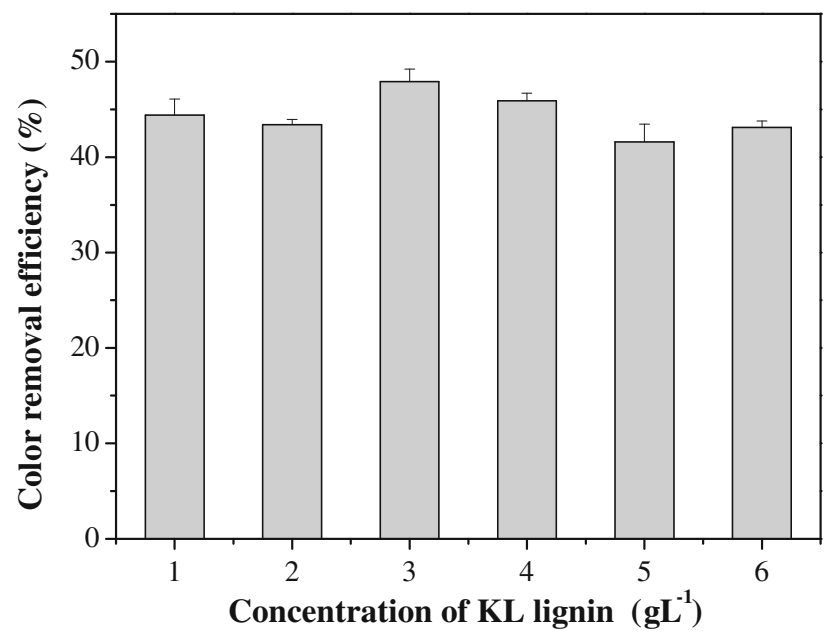

Fig. 3 Color removal rate by Pandoraea sp. B-6 on day 7 in different initial concentrations of kraft lignin. Data are presented as mean of three replicates with SE

second day but at significantly decreased levels. Initially, the color of the culture ranged from 2,651.5 to 18,333.3 CU but dropped to 1,474.2 CU for the lowest KL concentration and to $1,0431.7 \mathrm{CU}$ for the highest $\mathrm{KL}$ concentration on day 7. The decolorization rates of some bacterial strain, such as Bacillus sp. and Aneurinibacillus aneurinilyticus $[13,15]$ are reportedly more than $50 \%$. Although these decolorization rates are higher than that of Pandoraea sp. B-6, the KL concentrations in cultures of the other strains were $<0.6 \mathrm{~g} \mathrm{~L}^{-1}$, much lower than the $3 \mathrm{~g} \mathrm{~L}^{-1} \mathrm{KL}$ used in the present study.

\section{Bioassay of enzymes related to KL degradation}

Three major extracellular enzymes, including lignin peroxidase, manganese peroxidase, and laccase, carry out lignin degradation and have been well characterized in microorganisms [2]. The activity of these three enzymes from Pandoraea sp. B-6 was investigated at different $\mathrm{pH}$ values. Results after 3 days in culture of an initial $\mathrm{KL}$ concentration of $3 \mathrm{~g} \mathrm{~L}^{-1} \mathrm{KL}$ are shown in Fig. 4a. No obvious lignin peroxidase activity was observed at any $\mathrm{pH}$ value. The activities of manganese peroxidase and laccase were observed at $\mathrm{pH}$ values from 8 to 11 , with the maximum values of 2,274 and $537.4 \mathrm{U} \mathrm{L}^{-1}$, respectively, at $\mathrm{pH}$ 10. The activities of these two enzymes were almost undetectable at $\mathrm{pH}$ 7. These results indicate that manganese peroxidase and laccase are basophilic enzymes, although activities were suppressed $\mathrm{pH} 12$.

The activities of manganese peroxidase and laccase during a time course of $\mathrm{KL}\left(3 \mathrm{~g} \mathrm{~L}^{-1}\right)$ degradation are shown in Fig. $4 \mathrm{~b}$. The manganese peroxidase activity increased significantly during the initial 3 days with the maximum of 2,249.2 $\mathrm{U} \mathrm{L}^{-1}$ on the third day, decreasing thereafter. The laccase activity was maintained at a low level through the first 2 days. A significant increase in activity was observed on the third day with the maximum of $1,120.6 \mathrm{U} \mathrm{L}^{-1}$ on day 5. These results indicate that manganese peroxidase plays a crucial role in KL degradation by Pandoraea sp. B-6 beginning on the first day of culture; whereas laccase mainly functions in once the exponential growth phase is almost over. This is similar to the conclusions from previous reports regarding enzymes responsible for KL degradation in other bacterial species $[28,29]$. It may be that the secretion of ligninolytic enzymes by Pandoraea sp. B-6 occurs mostly during primary metabolism. As Pandoraea sp. B-6 is a Gram-negative bacterium, large lignin polymer molecules cannot be passively taken into the cell. Therefore, Pandoraea sp. B-6 produces extracellular ligninolytic enzymes to degrade the lignin polymer into fragments that can traverse the bacterial membrane. In addition, no obvious activity of lignin peroxidase was observed during the course of KL degradation, indicating that lignin peroxidase was not produced by Pandoraea sp. B-6. Some white-rot fungi and bacteria, such as Dichomitus squalens, Lentinula edodes [8], and Comamonas sp. B-9 [26], that are lignin degraders simultaneously produce manganese peroxidase and laccase, but did not secrete detectable levels of lignin peroxidase.

Table 1 Color removal (change in color units) in six different initial concentration of KL during the process of KL degradation by Pandoraea sp. B-6

\begin{tabular}{|c|c|c|c|c|c|c|}
\hline \multirow[t]{2}{*}{ Time (days) } & \multicolumn{6}{|c|}{ Different initial concentrations of KL } \\
\hline & $1 \mathrm{~g} \mathrm{~L}^{-1}$ & $2 \mathrm{~g} \mathrm{~L}^{-1}$ & $3 \mathrm{~g} \mathrm{~L}^{-1}$ & $4 \mathrm{~g} \mathrm{~L}^{-1}$ & $5 \mathrm{~g} \mathrm{~L}^{-1}$ & $6 \mathrm{~g} \mathrm{~L}^{-1}$ \\
\hline 1 & $2,651.5$ & $5,643.9$ & $8,712.1$ & $11,515.2$ & $15,075.8$ & $18,333.3$ \\
\hline 2 & $2,324.8 \pm 63.0$ & $4,980.9 \pm 82.6$ & $7,783.0 \pm 87.4$ & $9,914.6 \pm 166.1$ & $13,369.0 \pm 268.6$ & $16,267.27 \pm 203.7$ \\
\hline 3 & $1,801.0 \pm 73.5$ & $4,021.8 \pm 70.5$ & $6,090.5 \pm 62.1$ & $7,951.6 \pm 138.1$ & $10,985.5 \pm 128.4$ & $12,581.5 \pm 171.3$ \\
\hline 4 & $1,661.7 \pm 47.5$ & $3,549.5 \pm 58.1$ & $5,578.3 \pm 50.1$ & $7,545.9 \pm 126.2$ & $10,207.4 \pm 273.5$ & $11,683.4 \pm 250.3$ \\
\hline 5 & $1,571.0 \pm 64.3$ & $3,338.0 \pm 54.9$ & $5,339.9 \pm 83.4$ & $7,220.3 \pm 84.6$ & $9,702.3 \pm 133.4$ & $11,484.83 \pm 187.1$ \\
\hline 6 & $1,498.3 \pm 42.5$ & $3,269.5 \pm 101.9$ & $4,839.5 \pm 61.7$ & $6,398.6 \pm 120.6$ & $9,054.8 \pm 127.4$ & $11,044.65 \pm 257.5$ \\
\hline 7 & $1,474.2 \pm 55.0$ & $3,194.5 \pm 39.8$ & $4,539.0 \pm 72.6$ & $6,229.7 \pm 100.7$ & $8,804.2 \pm 130.4$ & $10,431.7 \pm 65.8$ \\
\hline
\end{tabular}



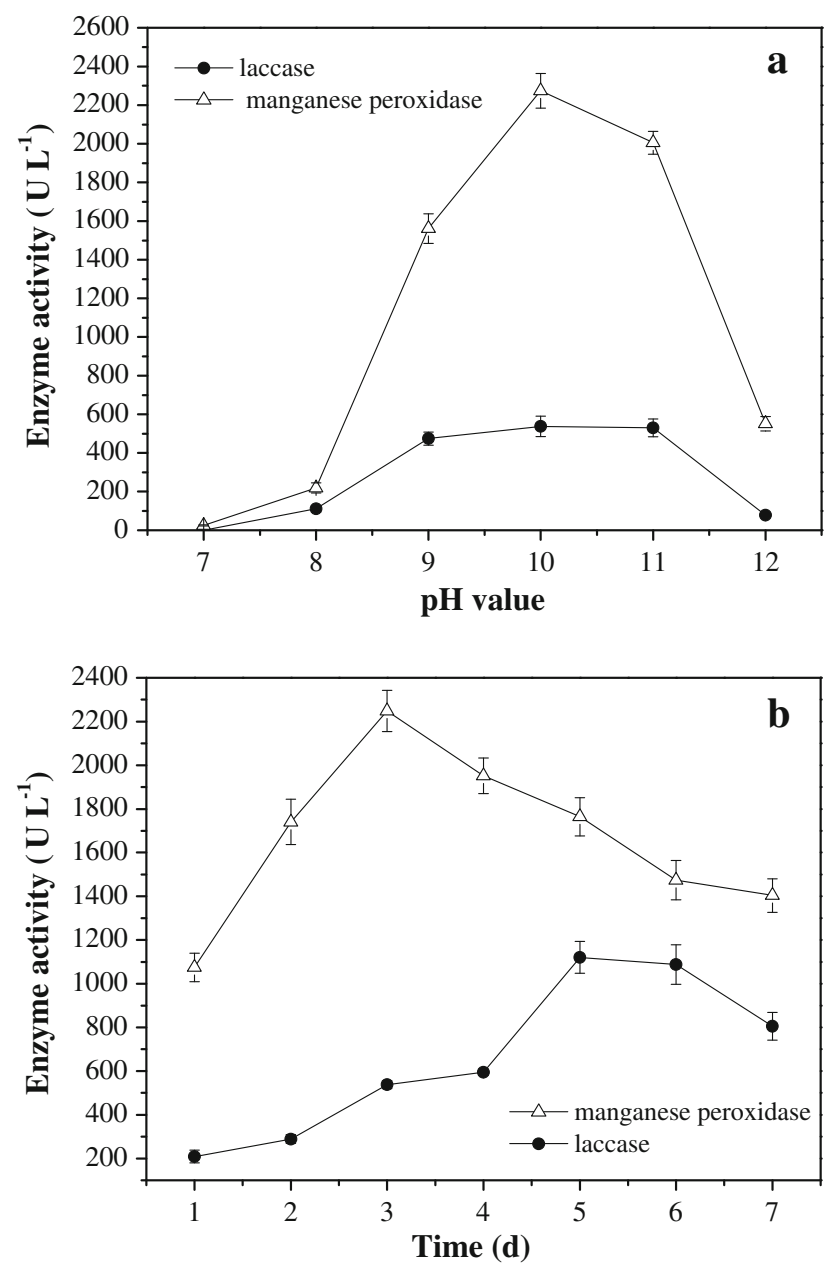

Fig. 4 The activity of manganese peroxidase and laccase during the process of kraft lignin degradation by Pandoraea sp. B-6. a The activity of manganese peroxidase and laccase at different $\mathrm{pH}$ values on day 3. b The activity of manganese peroxidase and laccase during 7 days at $\mathrm{pH}$ 10. Cell-free supernatants were used as enzyme source for ligninolytic enzyme assays. Values are mean of three replicates with SE

Lignin peroxidase is responsible for the oxidation of nonphenolic syringyl and biphenyl model compounds in certain types of lignin (like hardwood) and subsequent ring cleavage [8]. The mechanism of lignin biodegradation in the absence of lignin peroxidase production is not understood. It is conceivable that the efficiency of hardwood degradation by Pandoraea sp. B-6 and the other microorganisms mentioned above is relatively low.

Pandoraea sp. B-6 produces extracellular ligninolytic enzymes to degrade the lignin polymer. Activity of ligninolytic enzymes was detected in the cell-free supernatant of bacteria grown at alkaline $\mathrm{pH}$, and the level of manganese peroxidase and laccase was high in alkaline conditions. Unlike most lignin-degrading microorganisms, Pandoraea sp. B-6 produced manganese peroxidase and laccase to degrade lignin without need for an exogenous carbon source. We conclude that Pandoraea sp. B-6 can be directly used for treatment of black liquor without carbon source supplementation that increases the COD load of the system.

Metabolite characterization through GC-MS

The potential of Pandoraea sp. B-6 for the treatment of black liquor was further studied by identifying the ligninrelated aromatic compounds released during KL degradation using GC-MS analysis. The total ion chromatograph (TIC) patterns corresponding to the compounds extracted with ethyl acetate from the acidified supernatants obtained from the control (uninoculated medium sample) and degraded sample are shown in Fig. 5a, b and their peak identities are listed in Table 2. In the TIC pattern of control sample (Fig. 5a), acetic acid and phenol were identified at retention times (RTs) of 8.05 and 10.56, respectively. These two compounds are the two important intermediate metabolites during the breakdown of lignin by the microorganism [30, 31]. The presence of acetic acid and phenol may be attributed to the chemical oxidation of lignin due to aeration and agitation in the uninoculated culture. Moreover, some other lignin-related compounds were also identified, suggesting that minor degradation of KL occurs during the industrial production process [32].

As shown in Fig. 5b, the TIC of a sample of KL inoculated with Pandoraea sp. B-6 showed a significant increase in the number of peaks after 3 days of incubation as compared to the uninoculated sample, which indicated that a large number of low molecular compounds were released from the KL polymer as a result of the presence of the bacteria. Furthermore, many peaks identified on day 3 decreased after 7 days of incubation and new peaks appeared, indicating that low molecular weight compounds released form KL polymer initially were further degraded or mineralized. Based on results of the TIC for control and degraded samples, the process of KL degradation by Pandoraea sp. B-6 was divided into two steps: the initial depolymerization of $\mathrm{KL}$ and the degradation of the lower molecular weight compounds.

Many low molecular weight aromatic compounds were detected in the extract of the degraded sample (Fig. 5b, c; Table 2). These included veratryl alcohol (RT 11.86), cinnamic acid (RT 16.69), ethylguaiacol (RT 16.79), ferulic acid (RT 18.86), 4-hydroxycinnamic acid (RT 21.80), 3,4,5-trimethoxy benzaldehyde (RT 23.31), and lignophenols (RT 34.75), none of which were present in the control sample. The aromatic compounds identified in extract of degraded sample were due to the radical polymerization of guaiacyl $(G)$ units from precursor coniferyl alcohol, syringyl (S) units from precursor sinapyl alcohol, and p-hydroxyphenyl $(\mathrm{H})$ units from precursor p-coumaryl alcohol. G, S, and $\mathrm{H}$ units are considered the basic moieties 
Fig. 5 The total ion

chromatograph of trimethylsilyl derivatives of compounds extracted with trichloromethane from kraft lignin medium incubated with Pandoraea sp. B-6. a 0 days; $\mathbf{b} 3$ days; and $\mathbf{c}$ 7 days
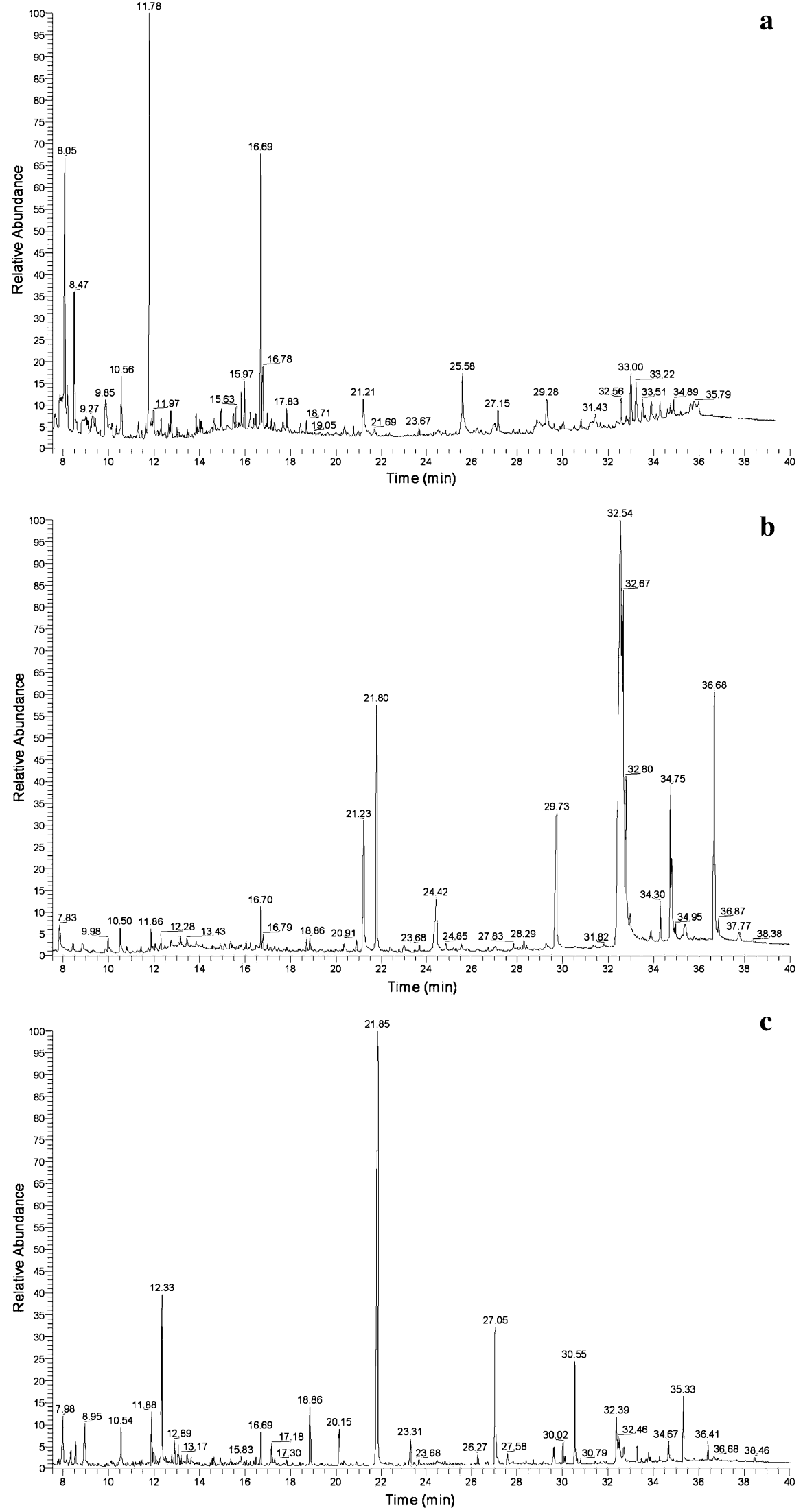
Table 2 Compounds identified as TMS derivatives in chloroform extract from control and bacterial degraded kraft lignin samples as given in Fig. 5

\begin{tabular}{|c|c|c|c|c|c|}
\hline \multicolumn{6}{|c|}{ Present in } \\
\hline No. & $\mathrm{RT}^{\mathrm{a}}$ & $\begin{array}{l}\text { Fig. } 4 \mathrm{a} \\
(0 \text { days })\end{array}$ & $\begin{array}{l}\text { Fig. } 4 b \\
\text { ( } 3 \text { days })\end{array}$ & $\begin{array}{l}\text { Fig. } 4 c \\
\text { ( } 7 \text { days })\end{array}$ & Compounds \\
\hline 1 & 8.05 & + & - & - & Acetic acid \\
\hline 2 & 8.47 & + & - & - & Methyl acetate \\
\hline 3 & 10.5 & - & + & - & Ethanedioic acid \\
\hline 4 & 10.56 & + & - & - & Phenol \\
\hline 5 & 11.78 & + & - & - & 3,5-Dimethyl-4-hydroxybenzaldehyde \\
\hline 6 & 11.86 & - & + & - & Veratryl alcohol \\
\hline 7 & 12.33 & - & - & + & 2-Hydroxy-5-methyl- $p$-benzoquinone \\
\hline 8 & 16.69 & - & - & + & Cinnamic acid \\
\hline 9 & 16.79 & - & + & - & Ethylguaiacol \\
\hline 10 & 18.86 & - & + & + & Ferulic acid \\
\hline 11 & 20.15 & - & - & + & 4-Hydroxy-3-methoxyphenylacetone \\
\hline 12 & 21.23 & - & + & - & Dibutyl phthalate \\
\hline 13 & 21.80 & - & + & - & 4-Hydroxycinnamic acid \\
\hline 14 & 21.85 & - & - & + & Guaiacyl vinyl ketone \\
\hline 15 & 23.31 & - & - & + & 3,4,5-Trimethoxy benzaldehyde \\
\hline 16 & 24.42 & - & + & - & 3,4,5-Trimethoxycinnamic acid \\
\hline 17 & 27.05 & - & - & + & 4-Hydroxy-3,5-dimethoxy benzaldehyde \\
\hline 18 & 29.73 & - & + & - & 4-Hydroxy-3-methoxybenzoic acid \\
\hline 19 & 30.02 & - & - & + & 2-Hydroxy benzyl alcohol \\
\hline 20 & 30.55 & - & - & + & Hexadecanoic acid \\
\hline 21 & 32.39 & - & - & + & Vanillyl methyl ketone \\
\hline 22 & 34.75 & - & + & - & Lignophenols \\
\hline 23 & 36.68 & - & + & + & $\begin{array}{l}\text { 3-3'-Dihydroxy-, } 4,-4^{\prime} \text { dimethoxy-6-formyl- } \\
\text { 6'-methyl-biphenyl carboxylic acid }\end{array}$ \\
\hline
\end{tabular}

${ }^{a}$ Retention time

\section{Conclusion}

In this paper, we report in the ability of the Pandoraea strain B-6 to efficiently degrade KL. Pandoraea sp. B-6 grew well in the sterile $\mathrm{KL}$ mineral salt medium without any co-substrate. For KL degradation by Pandoraea sp. B-6, the optimum $\mathrm{pH}$ was 10 and the optimum temperature was $30{ }^{\circ} \mathrm{C}$. In the range from $\mathrm{pH} 7$ to 12 , the greatest COD and color removal and the highest levels of activity of extracellular ligninolytic enzymes (manganese peroxidase and laccase) were observed at $\mathrm{pH}$ 10. Many intermediates formed during the process of bacterial degradation of were identified through GC-MS analysis. Our results indicate that Pandoraea sp. B-6 has significant potential for use in applications requiring for lignin degradation and for treatment of black liquor or other KL containing pollutants before their release into the environment.

Acknowledgments This work was funded by National Funds for Distinguished Young Scientists of China (50925417), National Natural Science Foundation of China (51074191), and the Key Project of National Natural Science Foundation of China (50830301). 
Open Access This article is distributed under the terms of the Creative Commons Attribution License which permits any use, distribution, and reproduction in any medium, provided the original author(s) and the source are credited.

\section{References}

1. Hammel KE (1997) Fungal degradation of lignin. In: Cadish G, Giller KE (eds) Driven by nature: plant litter quality and decomposition. CAB International, Wallingford, pp 33-45

2. Perez J, Munoz-Dorado J, de la Rubia T, Martinez J (2002) Biodegradation and biological treatments of cellulose, hemicellulose and lignin: an overview. Int Microbiol 5(2):53-63

3. Crawford DL (1980) Microbial degradation of lignin. Enzyme Microb Technol 2:11-22

4. Hatakka A (2001) Biodegradation of lignin. In: Hofrichter M, Steinbuchel A (eds) Biopolymers. Lignin, humic substances and coal, vol. 1. Wiley, Weinheim, p 129-180

5. Tuomela M, Vikman M, Hatakka A, Itavaara M (2000) Biodegradation of lignin in a compost environment: a review. Biores Technol 72:169-183

6. Masai E, Katayama Y, Fukuda M (2007) Genetic and biochemical investigations on bacterial catabolic pathways for ligninderived aromatic compounds. Biosci Biotechnol Biochem 71:1-15

7. Bugg TDH, Ahmad M, Hardiman EM, Singh R (2010) The emerging role for bacteria in lignin degradation and bio-product formation. Curr Opin Biotechnol 22:1-7

8. Tuor U, Winterhalter K, Fiechter A (1995) Enzymes of white-rot fungi involved in lignin degradation and ecological determinants of wood decay. J Biotechnol 41:1-17

9. Jokela JJ, Pellinen M, Salkinoja-Salonen M, Brunow G (1985) Biodegradation of two tetrameric lignin model compounds by a mixed bacterial culture. Appl Environ Microbiol 23:38-46

10. Gupta VK, Minocha AK, Jain N (2001) Batch and continuous studies on treatment of pulpmill wastewater by Aeromonas formicans. J Chem Technol Biotechnol 76:547-552

11. Ramachandra M, Crawford DL, Hertel G (1988) Characterization of an extracellular lignin peroxidase of the lignocellulolytic actinomycete Streptomyces viridosporus. Appl Environ Microbiol 54:3057-3063

12. Zimmermann W (1990) Degradation of lignin by bacteria. J Biotechnol 13:119-130

13. Chandra R, Raj A, Purohit HJ, Kapley A (2007) Characterisation and optimisation of three potential aerobic bacterial strains for kraft lignin degradation from pulp paper waste. Chemosphere 67:839-846

14. Chandra R, Singh S, Reddy MMK, Patel DK, Purohit HJ, Kapley A (2008) Isolation and characterization of bacterial strains Paenibacillus sp. and Bacillus sp. for kraft lignin decolorization from pulp paper mill waste. J Gen Appl Microbiol 54:399-407

15. Raj A, Chandra R, Reddy MMK, Purohit HJ, Kapley A (2007) Biodegradation of kraft lignin by a newly isolated bacterial strain, Aneurinibacillus aneurinilyticus from the sludge of a pulp paper mill. World J Microbiol Biotechnol 23:793-799

16. Raj A, Reddy MMK, Chandra R, Purohit HJ, Kapley A (2007) Biodegradation of kraft-lignin by Bacillus sp. isolated from sludge of pulp and paper mill. Biodegradation 18:783-792

17. Raj A, Reddy MMK, Chandra R (2007) Decolourisation and treatment of pulp and paper mill effluent by lignin-degrading Bacillus sp. J Chem Technol Biotechnol 82:399-406

18. Chandra R, Abhishek A (2011) Bacterial decolorization of black liquor in axenic and mixed condition and characterization of metabolites. Biodegradation 22:603-611
19. Chandra R, Abhishek A, Sankhwar M (2011) Bacterial decolorization and detoxification of black liquor from rayon grade pulp manufacturing paper industry and detection of their metabolic products. Biores Technol 102:6429-6436

20. Grover R, Marwaha SS, Kennedy JF (1999) Studies on the use of an anaerobic baffled reactor for the continuous anaerobic digestion of pulp paper mill black liquors. Process Biochem 34: $653-657$

21. Chai LY, Chen YH, Huang Y, Yang ZH (2010) Diversity of culturable microorganisms from erosive bamboo slips of Kingdom Wu. J Cent South Univ (Sci Technol) 41:1674-1679

22. Shintain N, Sugano Y, Shoda M (2002) Decolorization of kraft pulp bleaching effluent by a newly isolated fungus, Geotrichum candidum. Japan Wood Res Soc 48:402-408

23. Nakagawa Y, Sakamoto Y, Kikuchi S, Sato T, Yano A (2010) A chimeric laccase with hybrid properties of the parental Lentinula edodes laccases. Microbiol Res 165:392-401

24. Orth AB, Royse DJ, Tien M (1993) Ubiquity of lignin-degrading peroxidases among various wood-degrading fungi. Appl Environ Microbiol 59:4017-4023

25. Kapicha AN, Priora BA, Bothaa A, Galkinb S, Lundellb T, Hatakkab A (2004) Effect of lignocellulose-containing substrates on production of ligninolytic peroxidases in submerged cultures of Phanerochaete chrysosporium ME-446. Enzyme Microbiol Tech 34:187-195

26. Chen YH, Chai LY, Zhu YH, Yang ZH, Zheng Y, Zhang $\mathrm{H}$ (2012) Biodegradation of kraft lignin by a bacterial strain Comamonas sp. B-9 isolated from eroded bamboo slips. J Appl Microbiol 112:900-906

27. Giroux H, Vidal P, Bouchard J, Lamy F (1988) Degradation of kraft indulin lignin by Streptomyces viridosporus and Streptomyces badius. Appl Environ Microbiol 54:3064-3070

28. Hofrichter M (2002) Review: lignin conversion by manganese peroxidase (MnP). Enzyme Microb Technol 30:454-466

29. Leonowicz A, Cho NS, Luterek J, Wilkolazka A, Wojtas-Wasilewska M, Matuzewska A, Hofrichter M, Wesenberg D, Rogalski J (2001) Fungal laccase: properties and activity on lignin. J Basic Microbiol 41:185-227

30. Bugg TDH, Ahmad M, Hardiman EM, Rahmanpour R (2011) Pathways for degradation of lignin in bacteria and fungi. Nat Prod Rep 28:1883-1896

31. Hernes PJ, Benner R (2003) Photochemical and microbial degradation of dissolved lignin phenols: implications for the fate of terrigenous dissolved organic matter in marine environments. J Geophys Res 108:1-9

32. Hernandez M, Rodriguez J, Perez MI, Ball AS, Arias ME (1997) 13C NMR cross polarization and magic angle spinning (CPMAS) and gas chromatography/mass spectroscopy analysis of the products from a soda pulp mill effluent decolourised with two Streptomyces strains. Appl Microbiol Biotechnol 74:272-278

33. Jeffries TW (1990) Biodegradation of lignin-biochemistry of lignin-carbohydrate complexes. Biodegradation 1:163-176

34. Shin KS, Lee YJ (1999) Depolymerisation of lignosulfonate by peroxidase of the white-rot basidiomycete, Pleurotus ostreatus. Biotechnol Lett 21:585-588

35. Ksibi M, Amor SB, Cherif S, Elaloui E, Houas A, Elaloui M (2003) Photodegradation of lignin from black liquor using UV/ TiO2 system. J Photochem Photobiol 154:211-218

36. Hernandez M, Hernandez-Coronado MJ, Montiel MD, Rodriguez J, Arias ME (2001) Analysis of alkali-lignin in a paper mill effluent decolourised with two Streptomyces strains by gas chromatography-mass spectrometry after cupric oxide degradation. J Chromatogr 919:389-394

37. Hedges JI, Ertel JR (1982) Characterization of lignin by gas capillary chromatography of cupric oxide oxidation products. Anal Chem 54:174-178 